\title{
Topological Study of the Behavior of Inorganic Fine Powers and a Nanovesicle Hybridized Coating
}

\author{
Dong-Sung Seo, Dong-Pyo Kim, Fan-Long Jin, ${ }^{\dagger}$ and Soo-Jin Park ${ }^{\ddagger-}$ \\ Department of Fine Chemical Engineering \& Chemistry, Chmgnam National Lniversity, Daejeon 305-764, Korea \\ ${ }^{\dagger}$ School of Chemical and Materials Engineering. Jilin Institute of Chemical Technologv, Jilin 132022. P.R. China \\ -Department of Chemistry, Inha Lniversity, Incheon $402-751$, Korea. ${ }^{*}$ E-mail: siparkainha.ackr \\ Received October 28, 2008, Accepted December 12, 2008
}

\begin{abstract}
In this study, the surface of inorganic fine powders is hybridized with nanovesicles containing tocopheryl acetate prepared with hydrogenated lecithin via a coating process. From AFM and SEM analy ses it is found that the surface of the nanovesicle-coated fine powders lost their traditional topology and improved in terms of their roughness, skemess, and kurtosis. In addition, TEM observations revealed the formation of a $5 \mathrm{~mm}$ thick coating layer on the surface of the fine powders. These hybridized powders, in which bioactive materials such as tocopheryl acetate can be enbedded, can be employed as a part of a drug delivery system due to their special ability to control release rate and temperature selectivity. Physical properties of the powders, i.e, the different angle and friction coefficient, were excellent.
\end{abstract}

Key Wonds: Lecithin. Nanovesicle. Particle size. Fine powder. Topology

\section{Introduction}

Artificially prepared nanovesicles with similar organism cells that perform physiological functions are typically used in bio and cosmetic fields. In particular. nanobiochips. which have DNA or protein coated onto a solid surface and can be used as a biosensor. have attracted attention as a new field of organic-inorganic composites and as a fusion of bio-technology. Notably, several studies concerning multifunctional organism-friendly nanobio composites have been conducted. ${ }^{1.2}$

Recently many investigations have focused on the surface treatment or functional complexing of inorganic powders used in the cosmetics industry. ${ }^{3}$ In this field. several surfactants. oil. silicone. and other materials are used. ${ }^{+6}$ In the cosmetics field. various methods such as the addition of a surfactant to a powder. metal soap treatment. silicone treatment. and surface treatment of fluoric oil have been utilized to improve the dispersion of powders. ${ }^{78}$ Furthermore in-depth research into coatings of antimony dioxide. silica. and aluminum has yielded improvement in the usability and optic properties of cosmetic materials. ${ }^{3}$

In a previous paper. the authors reported the two-dimensional packing patterns of an amino acid surfactant and higher alcohols in an aqueous phase along with their associated packing parameters. ${ }^{9} \mathrm{~A}$ computational simulation of the steric hindrance between the hy'drophobic tails of a lamellar matrix composed of acyl glutamate/steary alcohol/behenyl alcohol according to the molecular dy namics was also performed. ${ }^{16}$ In the present study, nanovesicles were prepared from hydrogenated lecithin and tocopheryl acetate and an organicinorganic hybridized coating was formulated from the nanovesicles and fine powders. The properties of the nanovesicles and nanovesicle- coated fine powders were characterized by means of the particle size. weight variation, surface topology, dnig release rate. repose angle collapse angle and friction force measurements.

\section{Experimental}

Materials. The ampliphilic molecules used in the preparation of the nanovesicles were hydrogenated lecithin (Lesinol S10) provided by Nikko Chem. Pseudoceramide enployed as a reinforcing material for the nanovesicle film. was purchased from Neopharm Co. of Korea. The tocopheryl acetate used as a tracer in the drug release test was supplied by Sigma-Aldrich Chem. The fine powders used as a substrate in the coating of the nanovesicles were cosmetic level sericite (Miyoshi Kasei, Japan). talc (Ilshin Talc. Korea), and mica (Mikwang. Korea). $\mathrm{MgCl}_{2} \cdot 6 \mathrm{H}_{2} \mathrm{O}$, serving as an electrolyte, was purchased from Sigma-Aldrich Chem. 1.3-Butry lene gly col (Ducksan. Korea) was used as a solvent. The water used in this study was distilled water (resistivity: $18.0 \mathrm{M} \Omega \cdot \mathrm{cm}, \mathrm{pH}: 6.7$ ) prepared with the MilliQ Plus system. The chemical structures of the hydrogenated lecithins are shown in Figure 1.

Preparation of nanovesicles. Compositions of the nanovesicles were $2.0 \mathrm{wt} \%$ hydrogenated lecithin, $2.0 \mathrm{wt} \%$ 1.3-butrylene glycol. $0.3 \mathrm{wt} \%$ psesudoceramide. $0.2 \mathrm{wt} \%$ tocopherylacetate. and $95.5 \mathrm{wt} \%$ water. Hydrogenated lecithin and tocopheryl acetate were dissolved in water at $60^{\circ} \mathrm{C}$ (Solution I). Sericite was dissolved in 1.3-butrylene glycol at

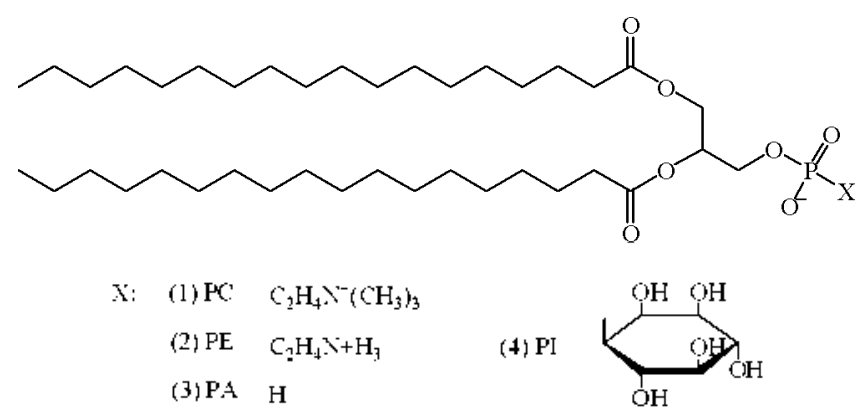

Figure 1. Structures of hydrogenated lecithins. 


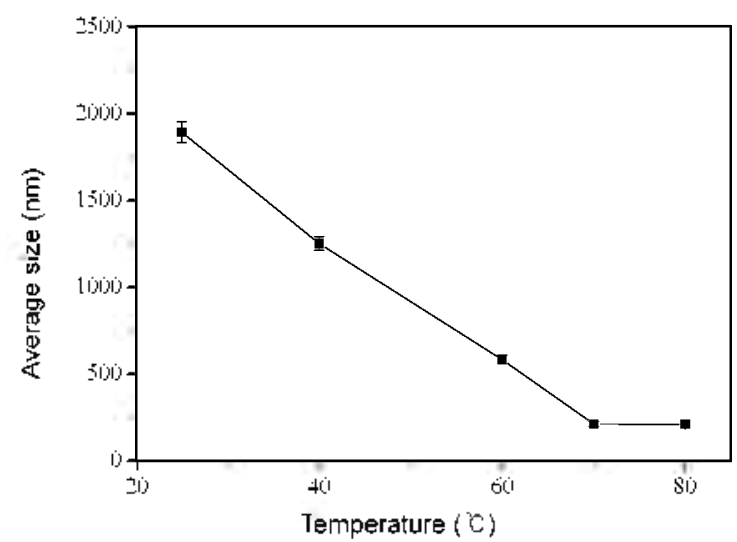

Figure 2. Average size of nanovesicles as a function of preparing temperature.

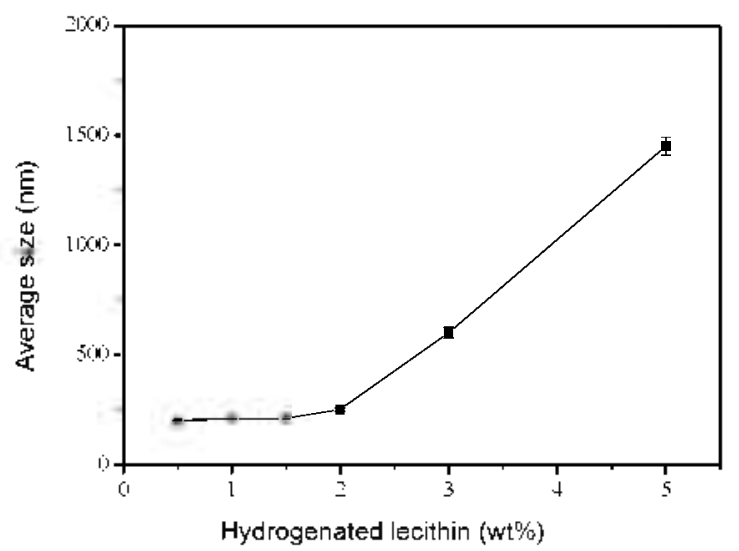

Figure 3. Average size of nanovesicles as a function of hydrogenated lecithin content.

$80^{\circ} \mathrm{C}$ (Solution II). Solution II was added to Solution I and the mixtures were dispersed using a microfluidizer for $5 \mathrm{~min}$.

Surface coating. $10 \mathrm{~g}$ of fine powder was placed into $50 \mathrm{~g}$ of water and the mixture was stirred at $60-70{ }^{\circ} \mathrm{C}$. $10 \mathrm{~g}$ of nanovesicle was then added into the mixture. which was then stirred. $10 \mathrm{wt} \%$ of the electrolyte solution was then sprayed into the mixture. The top solution was subsequently removed and the remaining solution was washed with water several times. After filtering, nanovesicle-coated fine powders were obtained by desiccation at $120^{\circ} \mathrm{C}$.

Characterization and measurement. The particle size of the nanovesicles was determined using a Particle Size Analyzer (Nicomp Autodilute 270, USA). The separation of the interfacial surface was imaged using a digital camera. The surface and section surface of the nanovesicle-coated fine powders were studied using a Field Emission Scanning Electron Microscope (Hitachi. S-4800. Japan) and a Transmission Electron Microscope (JEOL, JEM-2000 FXII. Japan).

Weight variation before and after coating the nanovesicles onto the surface of the fine powders was measured via a Thermogravimetric Analy sis (Buker. MTC-100SA. Germany) at a heating rate of $10^{\circ} \mathrm{C} \cdot \mathrm{min}^{-1}$ in a nitrogen atmosphere. The surface topology of the nanovesicle-coated fine powders was investigated using an Atomic Force Microscope (PSIA. XE-100, Korea). The properties and thickness of the nanovesicle-coated fine powders were investigated wia Electron
Spectroscopy for Chemical Analysis (VG Scientific, ESCA LAB 250. UK).

The tocopheryl acetate-dipped nanovesicles were characterized using a UV-Visible Spectrophotometer (JASCO, V-550. USA), which was also employed to determine the drug release rate.

Measurement of properties. The repose angle and collapse angle of the nanovesicle-coated fine powders were measured with a Powder Tester (PT-N. Hosokawa-Micron. Japan). To determine the effect of nanovesicle-coated fine powders on the friction force of artificial skin, initial and dy namic friction coefficients were measured using a friction-meter (Vitrodyne. LG House and Health Care. Research Park, Korea).

\section{Results and Discussion}

Particle size of the nanovesicles. Nanovesicles containing $1.5 \mathrm{w} \%$ hydrogenated lecithin were prepared by sonication. ${ }^{.}$ The particle size of the nanovesicles was measured with a Particle Size Analyzer. The average size is shown in Figure 2. As shown in Figure 2, the average size of the nanovesicles decreased as the temperature was increased to $70^{\circ} \mathrm{C}$ and did not significantly vary thereafter. The average size of the nanovesicles at $70^{\circ} \mathrm{C}$ and $80^{\circ} \mathrm{C}$ were $210 \mathrm{~nm}$ and $208 \mathrm{~nm}$.

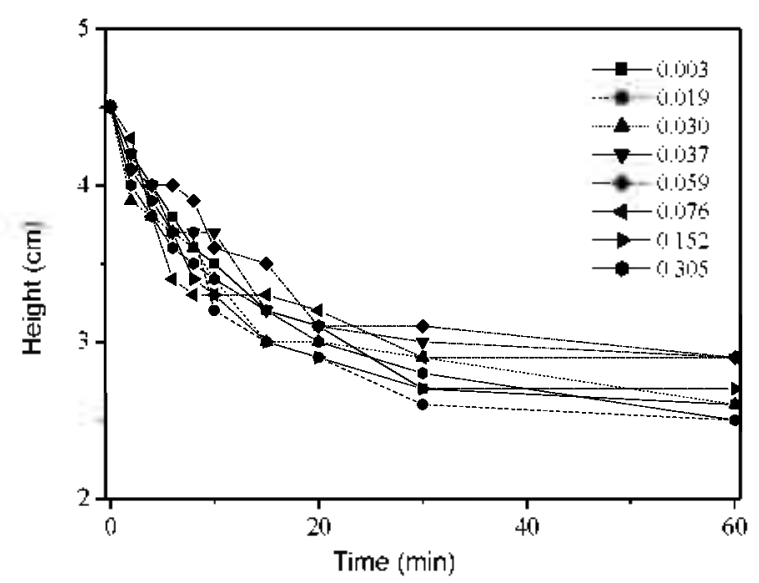

Figure 4. Flocculating rate between nanovesicles and fine powders by titrating of $\mathrm{MgCl} \mathrm{l}_{2}$ solution.

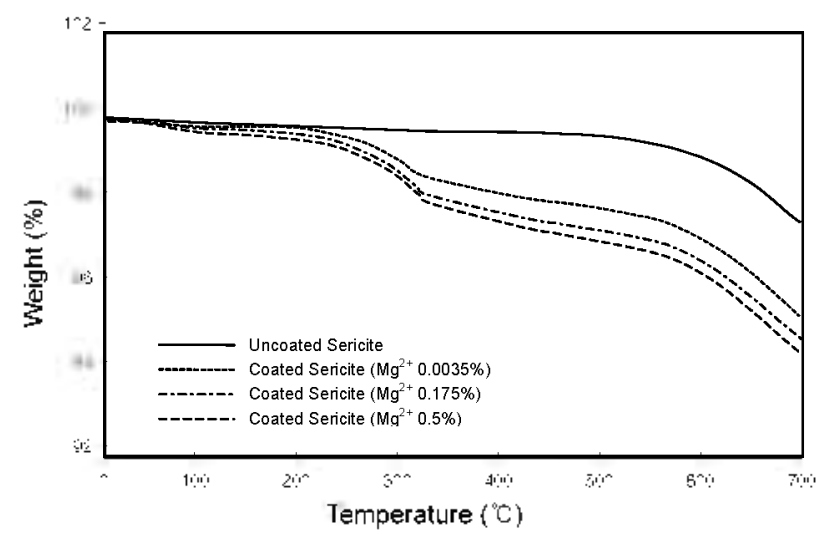

Figure 5. TGA curves of the neat sericite and the nanovesicle-coated sericites by various titrating $\mathrm{Mg}$ concentration. 
respectively. From these results. the optimal temperature was determined to be $70^{\circ} \mathrm{C}$.

The effects of the hydrogenated lecithin content on the particle size of the nanovesicles prepared at $70{ }^{\circ} \mathrm{C}$ were investigated. The average size of these particles is shown in Figure 3. The average size of the nanovesicles did not significantly vary below $2 \mathrm{wt} \%$ of hydrogenated lecithin. being maintained at $200 \mathrm{~nm}$ : however, it sharply increased above this content level. Thus. the optimal amount of added hydrogenated lecithin was $2 \mathrm{wt} \%$.

From these results, it can be concluded that the optimal conditions for the preparation of the nanovesicles are a temperature of $70^{\circ} \mathrm{C}$ and a hydrogenated lecithin content of 2 $\mathrm{wt} \%$.

Coating of the nanovesicles. The fine powders used in this study are talc, mica, and sericite. These powders not only increase the whiteness of cosmetics. but also decrease preparation cost. These powders have an average size of $10 \mu \mathrm{m}$ and appear as flakes. As such. nanovesicles can easily be coated onto the surface of the powders. An electrolyte also plays an important role in the coating of nanovesicles on the surface of the powders. ${ }^{12}$ Commonly. $\mathrm{MgCl}_{3}, \mathrm{MgSO}_{+} \mathrm{CaCl}_{3}$. $\mathrm{CaSO}_{4} . \mathrm{AlCl}_{3}, \mathrm{Al}\left(\mathrm{SO}_{4}\right)_{3}, \mathrm{ZnCl}_{2}$. and $\mathrm{ZnSO}_{4}$ are used as electrolytes. As many of these electrolytes irritate skin. however, $\mathrm{MgCl}_{2} \cdot 7 \mathrm{H}_{2} \mathrm{O}$ was chosen as an electrolyte in the present work.

Figure 4 shows the titration height of the $\mathrm{MgCl}_{2}$ solution as a function of time. The height decreased with the elapsed of 30 minutes. but did not vary significantly beyond this time point. When the $\mathrm{MgCl}_{2}$ solution was initially titrated. the surface charge of the nanovesicles decreased. which decreased the total potential energy. This produced an attraction force between the powders. This attraction force initially caused the nanovesicle powders to flocculate. leading them to connect with the network and form a bridge on the surface of the fine powders. ${ }^{13}$

Surface topology. Figure 5 shows TGA thermograms of nanovesicle-coated sericite and uncoated sericite. The initial weight loss of the uncoated sericite began at $500^{\circ} \mathrm{C}$ and the weight decreased significantly at approximately $600^{\circ} \mathrm{C}$ due to disconnection of the bound water inside the crystal lattice. The initial weight loss (2 wt\%) of the nanovesicle-coated (a)

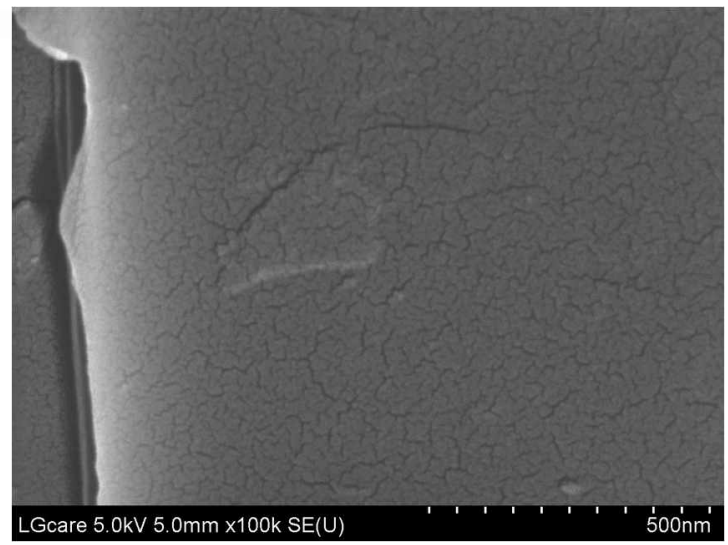

(b)

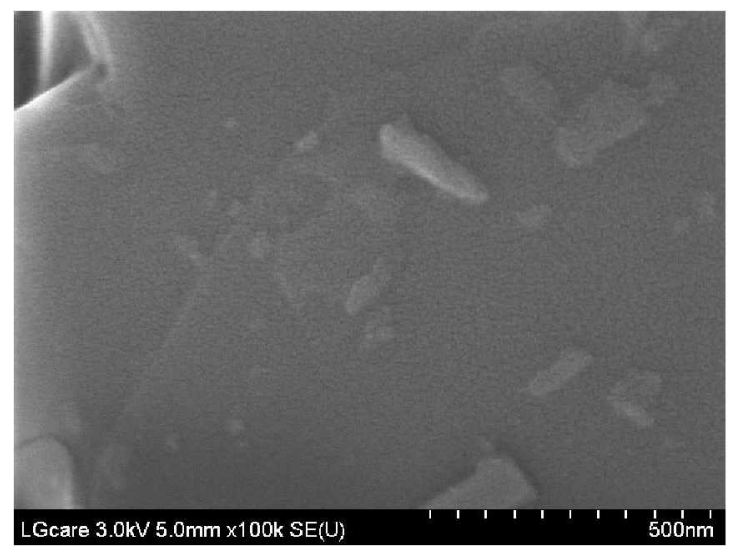

Figure 6. SEM photographs of the neat mica and the nanovesicle-coated mica $(\times 100,000)$.

sericite occurred at 200-350 $\mathrm{C}$ due to disconnection of the hydrogenated lecithin. The second weight loss $(0.5 \mathrm{wt} \%)$ occurred at $350-450^{\circ} \mathrm{C}$ : this was due to decomposition of the tocopheryl acetate and sericite. ${ }^{14}$

The nanovesicles containing tocopheryl acetate were characterized via UV-VIS at $200-900 \mathrm{~mm}$. The results showed peaks at $210 \mathrm{~nm}$ and $283 \mathrm{~nm}$, characteristic of tocopheryl acetate. $^{15}$

The surfaces of the nanovesicle-coated fine powders and uncoated powders were investigated via SEM. Figure 6 shows SEM photographs of the front of the uncoated mica along with

Table 1. Quantitative analysis of the neat sericite and the nanovesicle-coated sericite from survey scan

\begin{tabular}{|c|c|c|c|c|c|c|}
\hline & Element & Peak BE & Height counts & FWHM (eV) & Atom $(\%)$ & Reference $\mathrm{O}$ \\
\hline \multirow{6}{*}{ Before } & $\mathrm{Al} \mathrm{2p}$ & 73 & 14809.6 & 2.28 & 13.2 & 0.22 \\
\hline & $\mathrm{Si} 2 \mathrm{p}$ & 102 & 30151.8 & 3.95 & 18.9 & 0.3 \\
\hline & C ls & 285 & 4079.9 & 4.42 & 20 & 0.03 \\
\hline & $\mathrm{K} 2 \mathrm{p}$ & 295 & 25470.6 & 3.53 & 40 & 0.07 \\
\hline & $\mathrm{O}$ Is & 533 & 320364.0 & 3.43 & 60.9 & 1.00 \\
\hline & Mg ls & 1306 & 9012.3 & 2.49 & 1.0 & 0.02 \\
\hline \multirow{6}{*}{ After } & Al $2 p$ & $7 \hat{3}$ & 9918.4 & 2.7 & 8.8 & 0.24 \\
\hline & Si $2 p$ & 101 & 18483.0 & 2.46 & 11.6 & 0.32 \\
\hline & $\mathrm{C} \mathrm{Is}$ & 284 & 80298.0 & 3.87 & 41.2 & 1.13 \\
\hline & K $2 p$ & 293 & 19374.7 & 3.52 & 1.6 & 0.04 \\
\hline & O ls & 532 & 168547.0 & 4.03 & 36.4 & 1.00 \\
\hline & $\mathrm{Mg} \mathrm{Is}$ & 1306 & 2948.9 & 1.94 & 0.3 & 0.01 \\
\hline
\end{tabular}


the nanovesicle-coated mica. The surface of the uncoated mica shows many cracks and pores. The nanovesicle-coated mica lost its traditional topology and exhibited a clean surface, most likely because the cracks and pores in the mica surface were coated $w$ ith the nanovesicles. ${ }^{16}$

Figure 7 shows topological images of the uncoated sericite and the nanovesicle-coated sericite. The uncoated sericite shows a rough surface and edges. The surface of the nanovesicle-coated sericite shows improved roughness and kuttosis compared with the uncoated sericite. This is consistent with the SEM results.

The properties and thickness of the nanovesicle-coated sericite were investigated via ESCA and TEM. Table 1 shows the results of a quantitative analy sis of the nanovesicle-coated sericite and the uncoated sericite. After coating the nanovesicles. the $\mathrm{Al}, \mathrm{Si} . \mathrm{K}, \mathrm{Mg}$, and $\mathrm{O}$ content decreased and the content of $\mathrm{C}$ significantly increased. Figure 8 shows a TEM photograph of the nanovesicle-coated sericite. The arrow indicates that the layer differs at the interior region of the sericite. These results confirm that the nanovesicles were coated onto the surface of the sericite. The thickness of the coating calculated from the TEM photograph is close to $5 \mathrm{~nm}$.

Properties of the nanovesicle-coated fine powders. The release rates of the nanovesicle-coated sericite and the nanovesicle-dipped sericite in $\mathbf{5 \%}$ tocopheryl acetate solution were determined. and the results are displayed in Figure 9. The nanovesicle-dipped sericite initially released a consider-

(a)

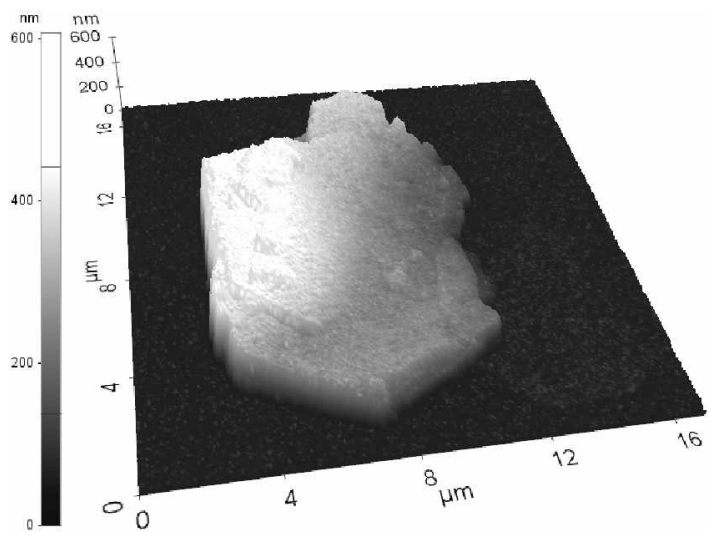

(b)

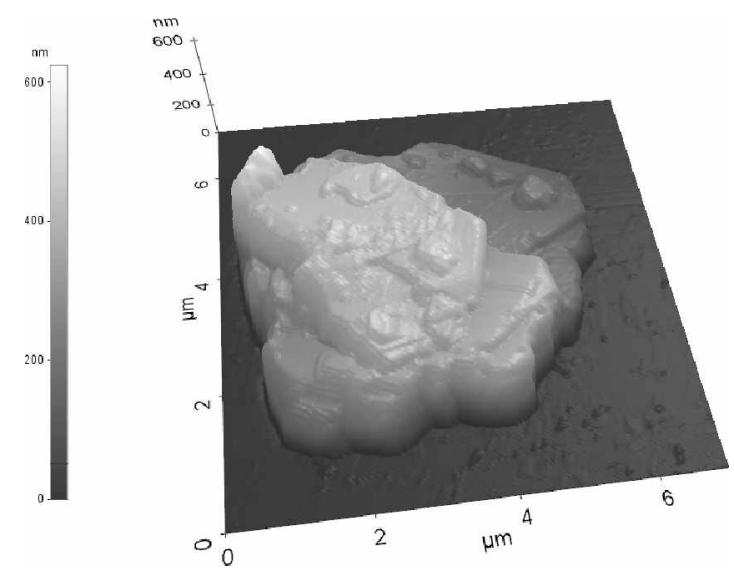

Figure 7. Topological mages of the neat sericite (a) and the nanovesicle-coated sericite (b). able amount of tocopheryl acetate, whereas the nanovesiclecoated sericite showed a low initial release rate that increased over time. The release rate at $40^{\circ} \mathrm{C}$ is higher than that at $25^{\circ} \mathrm{C}$, as the double layer of the nanovesicles serves as a biological barrier that controls the release rate of the tocopheryl acetate. $^{\text {? }}$

The repose angle and collapse angle of the nanovesiclecoated fine powders were neasured with a Powder Tester. ${ }^{18}$ The difference angle (difference between the repose angle and the collapse angle) was calculated. and the results are shown in Table 2. The difference angle of the nanovesicle-coated fine powders was larger than that of the silicone-coated fine powders with an identical particle diameter. The difference angle is related to the fluidity of fine powders. The fluid properties can be characterized by means of friction coefficient measurements.

The initial and dy namic friction coefficients of the nanovesicle-coated fine powders were investigated, and these results are shown in Table 3 . The nanovesicle-coated fine powders have lower initial and dy namic friction coefficients compared to those of the silicone-coated fine powders. The nanovesicle-coated fine powders are characterized by lower and stable wave-type fluctuations and excellent fluidity conpared with the silicone-coated fine powders.

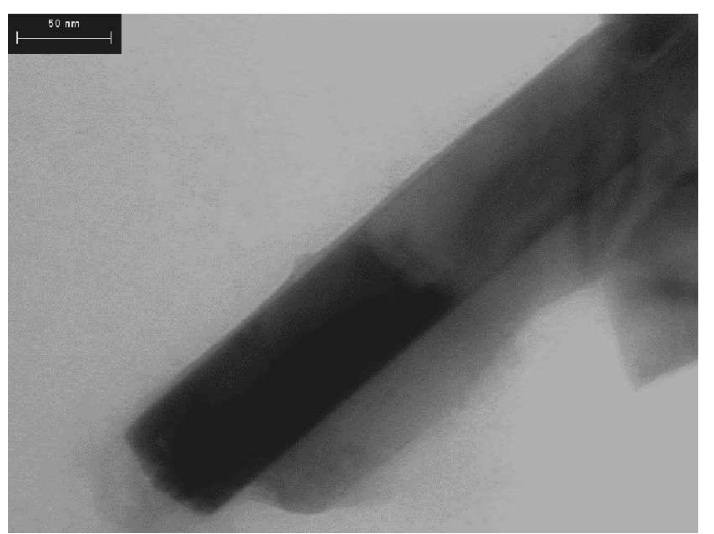

Figure 8. TEM photograph of the nanovesicle-coated sericite $(x$ $240,000)$.

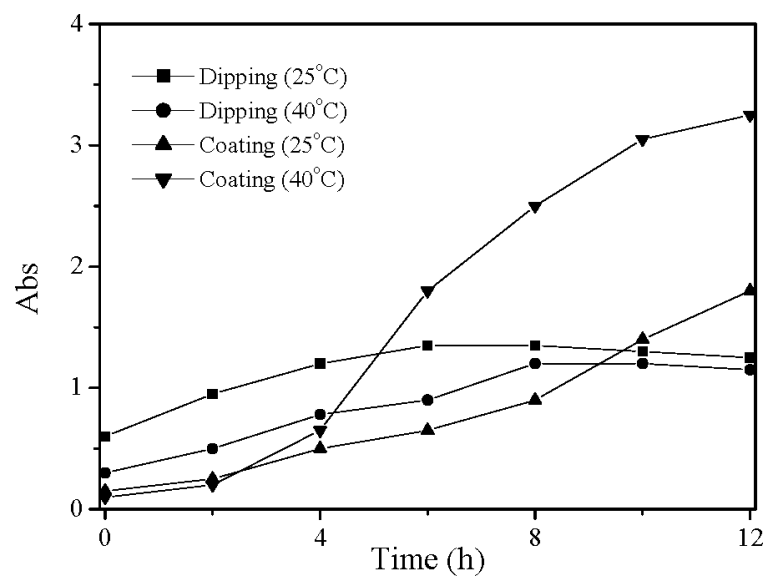

Figure 9. Releasing rates of the nanovesicle-coated sericite and the dipped sericyite in $5 \%$ tocopheryl acetate solution. 
Table 2. Difference $(\Delta)$ angle of the nanovesicle-coated and the silicone-coated powders.

\begin{tabular}{lcc}
\hline \multicolumn{1}{c}{ Sample } & $\Delta$ angle $\left(^{0}\right)$ & $\mathrm{D}_{40}$ \\
\hline Silicone coated Talc & 9.8 & \\
Nanovesicle coated Talc-1 & 11.2 & $5 \mu \mathrm{m}$ \\
Nanovesicle coated Talc-2 & 12.5 & \\
Nanovesicle coated Talc-3 & 12.0 & \\
Siliconte coated Sericite & 7.1 & \\
Nanovesicle coated Sericite-1 & 9.0 & $5 \mu \mathrm{m}$ \\
Nanovesicle coated Sericite-2 & 9.4 & \\
Nanovesicle coated Sericite-3 & 8.9 & \\
Silicone coated Mica & 10.4 & \\
Nanovesicle coated Mica-1 & 11.7 & $14 \mu \mathrm{m}$ \\
Nanovesicle coated Mica-2 & 13.8 & \\
Nanovesicle coated Mica-3 & 12.9 & \\
\hline
\end{tabular}

Table 3. Friction coefficients of the nanovesicle-coated and the silicone-coated powders

\begin{tabular}{lcc}
\hline \multicolumn{1}{c}{ Sample } & Initial $\left(\mathrm{l}_{1}\right)$ & Dynamic $(\mu)$ \\
\hline Silicone coated Talc & $21.6 \pm 0.55$ & $20.0 \pm 0.61$ \\
Nanovesicle coated Talc-1 & $19.0 \pm 0.72$ & $18.8 \pm 0.27$ \\
Nanovesicle coated Talc-2 & $18.2 \pm 0.24$ & $17.8 \pm 0.17$ \\
Nanovesicle coated Talc-3 & $18.9 \pm 0.97$ & $16.5 \pm 0.38$ \\
Silicone coated Sericite & $17.2 \pm 0.08$ & $16.0 \pm 0.30$ \\
Nanovesicle coated Sericite-1 & $16.2 \pm 0.47$ & $15.5 \pm 0.18$ \\
Nanovesicle coated Sericite-2 & $14.1 \pm 0.33$ & $14.5 \pm 0.08$ \\
Nannovesicle coated Sericite-3 & $13.8 \pm 0.87$ & $14.4 \pm 0.14$ \\
Silicone coated Mica & $17.4 \pm 0.97$ & $15.9 \pm 0.40$ \\
Nanovesicle coated Mica-1 & $14.2 \pm 0.32$ & $15.1 \pm 0.73$ \\
Nanovesicle coated Mica-2 & $12.6 \pm 0.42$ & $14.6 \pm 0.69$ \\
Nanovesicle coated Mica-3 & $12.1 \pm 0.71$ & $13.8 \pm 0.54$ \\
\hline
\end{tabular}

\section{Conclusions}

Nanovesicles and nanovesicle-coated fine powders were prepared and their properties were characterized in this study. The average size of nanovesicles containing hýdrogenated lecithin was determined to be $200 \mathrm{~nm}$. TGA results indicated that the weight loss at $450^{\circ} \mathrm{C}$ was $2.5 \mathrm{wt} \%$. This weight loss stems from decomposition of the nanovesicles. The surface of the uncoated mica showed many cracks and pores. while the nanovesicle-coated mica exhibited a clean surface. According to the AFM results, the surface of the nanovesicle-coated sericite was significantly improved in terms of its roughness and kurtosis. The nanovesicle-coated sericite showed a low initial release rate that increased with time. The release rate at $40^{\circ} \mathrm{C}$ was higher than that at $20^{\circ} \mathrm{C}$. The difference angle of the nanovesicle-coated fine powders was larger than that of the silicone-coated fine powders with an identical powder diameter.

\section{References}

1. Kim, K. H.; Lee, S. Y.; Kim, S.; Teong, S. G. Cimr Appl. Phws. 2008, 8,687

2. Xu, L: Yu, H.: Aklras, M. S.: Han, S. T.: Osterfeld, S.: White. R. L.; Poumand, N.: Wang, S. X. Biosensor Bioelectron 2008, 24, 99.

3. Kani, T.; Tamonoki, M.: Suzuki, T.; Tsukada, M.; Kamiya, H. Powder Techol 2007, 176.99.

4. Singh, A. Van Hamme, J. D.; Ward, O. P. Biotechnol. Adh. 2007, 25.99 .

5. Kleman, R.: Ashley, D. A.; Brown, J. H. Ind Crop Prod. 2008, 28,361 .

6. Noomen, A.; Haieb, S.; Parrot-Lopez, H.: Kalfat, R.: Fessi, H.; Amdouni, N.: Chevalier, Y. Mater. Sci. Eng. C 2008, 28,705.

7. Wen, X; Li, M.; Pi, P; Chen, T; Yang, Z. Colloid Surface A $2008,327,103$

8. Yabe, S.: Sato. T. J. Solid State Chem. 2003, 171.7.

9. Seo, D. S.; Kim, J. C.; Sohn, H. H.; Cho, W. G.; Lee, S. U.; Kim, E. Y.: Tae, G.: Kim. I. D.: Lee, S. Y., Lee, H. Y. J. Colloid Interface Sci. 2004, 273, 596.

10. Seo, D. S.; Kim, J. C.; Kim, D. P. J. Ind Eng. Chem., in presss.

11. Bae, D. H.: Shin, J. S.: Jin, F. L.; Park, S. I. Bull. Korean Chem. Soc. 2009, in press.

12. Miller, D.; Löfler, M. Colloid Stirface A 2006, 288, 165.

13. Lien, M. H.: Huang, B. C.; Hsu, M. C. J. Chromatogr . 1993. 645,362

14. Jin, F. L.; Park, S. T. Polwm. Degrad Stab. 2007, 92, 509

15. Shibata, N.: Tomita, N. Biomaterials 2005, 26,5755.

16. Jin, F. L.: Park, S. T. M Aater. Sci. Eng. A 2008, $178,402$.

17. Park, S. T.; Lee, Y. M; Hong, S. K. Colloid Surface B 2006, $+7,211$.

18. Kim. E. H.: Chen. X. D: Pearce, D. Powder Techol 2005. 158.21. 